\title{
Analysis for the Drama Image and Musical Image of Musetta in the Aria Stroll in the Street
}

\author{
Tiandan Zhang ${ }^{1}$, Binghong Wang ${ }^{2}$ \\ ${ }^{1}$ Ezhou Polytechnic, Ezhou, 436000, China \\ ${ }^{2}$ Ezhou Xinmin Street Primary School, Ezhou, 436000, China
}

Keywords: Stroll in the Street, musical image, drama image, Artist's Life

Abstract. Puccini is the greatest opera composer in Italy after Verdi, who is the representative of
"verism" opera school. In this paper, the drama image and musical image of Musetta is discussed in
details through analyzing the aria Stroll in the Street in Puccini's opera Artist's Life.

\section{Story introduction}

Poet Rudolph, painter Macello, musician Shawnal and philosopher Conerly live together in a shabby house. Though their lives are poor but they are happy. One day, Rudolph met needlewoman Mimmy by accident in their house and he fell in love with her at the first sight. Be brought her into the pub where his friends were dining together. There, Macello met his past lover Musetta, who was accompanied by an old man, Alcindoro, who was chasing after her. However, she loves Macello all the time. After tease and show-off, Macello tried to get rid of the old man and fell into Macello's arms. Several months after, the relation between them became worse and worse. Moreover, the relation between Mimmy and Rudolph was on the brink of breaking. Mimmy got serious lung disease. When she went to meet with Rudolph for the last time, they got together again and planed their future. However, Mimmy died at last and Rudolph became sorrowful. As a result, Musetta and Macello got together because of the profound impact of the sufferings between Mimmy and Rudolph.

\section{Analysis for the drama image of Musetta}

The protagonist in Stroll in the Street is Musetta, a young and beautiful prostitute who dares to love and hate. In the New Year, she met her previous lover, poor painter Macello on the street. To attract his attention and inspire his jealousy, Musetta sang this aria.

\subsection{Musetta and Alcindoro}

Musetta is a young and beautiful prostitute who dares to love and hate. Sometimes, because of poverty, she has to associate with rich people to gain some material comforts. Alcindoro meets her standard completely. There isn't any feeling between she and Alcindoro, expect money interests. Therefore, she expresses her feelings with the aria Stroll in the Street without considering the worries and annoyance of Alcindoro when she meets her lover on the street, so as to draw Macello's attention.

\subsection{Musetta and Macello}

Macello is a poor painter. His love to Musetta is loyal and pure. However, he can provide Musetta with nothing but love. He is very ambivalent and self-abased. When he sees Musetta associating with upper-class characters, he gets hurt. $\mathrm{He}$ is filled with indignation and self-abasement. When Musetta sings the waltz, there are three interruptions. For instance, when Musetta sings "everyone loves me and appreciates me completely", Macello sings "dear friends, I can't bear it anymore." When Musetta sings "how happy”, Macello sings "this song is irritating”. We can see the pain in Macello. Finally, Macello can not control himself anymore. He rushes out and hugs and kisses Musetta fiery. They take off their disguises and get together finally.

\section{Musical analysis for the aria Stroll in the Street}

In the aspect of musical form, Stroll in the Street adopts the form of $\{A+B+A\}$. The period $A$ 
consists of two eight-bar musical phrases. The characteristic of the melody mainly lies in the steps of intervals. This melody begins with a fine flowing speed at the $3 / 4$ beat. Apart from maintaining the step intervals in the first period, a musical scale sequence beyond octave is added. The tonality of the second period is shifted to the subdominant of E major key in period A. In addition, the rhythm and pattern of syncopation is adopted in many parts in this period, which add the flexibility of the melody largely. Musetta tells her desire for love in this period. The third period is similar with the first period. The tonality is brought back to the E major key. The ending is natural and unrestrained. In addition, the accompaniment is ended with only two tones, which depicts the unique characteristic of Musetta. There are several short-shifting tones in the aria, which highlights that Musetta is really a wild girl, who is beautiful but not vulgar. Puccini spent great spirits in each period. Each rhythm and chord contains powerful appeal of music. They describe the vixenish and coquettish musical image of Musetta reasonably and vividly. There are 52 bars in the aria in total, which can be divided into three periods: first, the appearance music image of Musetta; second, the ambivalent inner world music image of Musetta; and third, the long for love music image of Musetta.

\subsection{The appearance music image of Musetta (1-20 bars)}

The prelude is allegretto arpeggio, which is very gentle. And then, a quaver staccato breaks the peace of the night. At that time, the whole world becomes quilt. Every little movement can be felt clearly. Then, three light staccatos like heartbeats, boom, boom, boom, not in a hurry express the enviousness of Musetta, as if a rabbit will jump out from her chest immediately. However, she had to control herself, because she will sing the flowing period to express her love to Macello. A low octave is taken as the support of the melody to play the basic material and rhythmic pattern of the melody.

The $5^{\text {th }}$ to $12^{\text {th }}$ bars are very fair-sounding. The speed returns to the original one, which is the typical rhythm of waltz. The music is the dotted half note without large melody fluctuations. It is very sweet. The low pitch continues with triple time and then it is changed a little. We can see the unique effect generated by a period of simple melody. After the separation of Musetta and Macello, the music rises slowly. She begins to call her lover lightly in a manner of monologue. This period contains the major musical image of Musetta. The composer had very specific requirements on the emotions. A tempo (very happy): the $3 / 4$ beat is still adopted to express the activeness. The major triad arpeggios on the E major key are played with low pitch. How charming is the moonlight in the night. Under the emotion requirement of "dolce", coherent chords jump into the high pitch area. Along with the several short-shifting tones in the melody, the bright and clear, free and easy characteristic of Musetta is expressed naturally. And then, quarter notes are played, which are tighter and more active than the previous dotted half note. The appearance of dotted half note and application of primes accompaniment part express her deep feeling call to her lover and her long for sweet love. The accompaniment part is not changed at all. A seven degree interval is played after a short-shifting tone in the ending period. The several bars describe the musical image of Musetta completely.

When Musetta meet her long-lost lover Macello, her love to him is inspired again. To attract his attention, Musetta sing this song. Of cause, the audiences contain Macello and his friends and guests. Musetta is such a bold girl. After listening to her song, people look at her with supervise, because they don't know why she sing this song. In the following bars from 13 to 20, the question is answered. Musetta is a beautiful and romantic girl. Therefore, there is a two-line octave b tone at the $17^{\text {th }}$ bar, which can tell us the personality of Musetta clearly: she is vixenish, wild, confident and coquettish. She provokes the audience with her song. In addition, she wants to draw Macello's attention, which lay a foundation for the following period.

\subsection{The ambivalent inner world music image of Musetta}

The music image of Musetta's ambivalent inner world can be divided into two parts. The first part (21-28 bars) describes her aspect of confidence; while the second part (29-36 bars) describes her aspect of self-abasement. From the very beginning of his period, the music becomes gentle and light, because Musetta does not complete her tell and she is going to sing her actual aspect to the 
audience and Macello. The speed of this period is allegro moderato and the strength is this period is dolcissimo. The musical notes are dense in this period and the vocal music labor is intensive. Although the main melody is still eighth notes, the accompaniment is also eighth notes, which form perfect intervals of octave chords together with the melody. This period of melody is played by instruments and then great techniques are shown in the song. What' more, the song become more and more difficult and reaches the climax at last. The objective of this period is to describe the delicate inner world of the opera character Musetta in details to highlight the thematic feature of the opera character perfectly. Here, Musetta's though about love is expressed, both the happy one and the sad one. Moreover, her psychological states for the desired but uncertain future are described. Otherwise, there shouldn't be so many "hesitations" (the application of pauses) in the ascending melody, which is with relatively strong doubt. Moreover, there are many short-shifting tones and big jumps in intervals. They can express that Musetta is very excited. She is shown how charming she is to Macello. The males in the situation are captivated by her. She is a beautiful girl, who conceals her real aspect. Fearing that Macello thinks she is not beautiful and energetic any more, she is trying to tell Macello that she enjoyed rich life during the period he deviating from her.

And then, the following bars from 29 to 36 bring the whole musical movement to the climax. This period begins with an unaccented beat. The gentle song moves the whole audience. Everyone things Musetta is happy: she enjoys fine wines, beautiful clothes, delicate decorations. All of these make her very elegant. Everybody appreciates her and admires her. However, is she really happy? The whole period is sung with accented beats to show her confidence for others. However, the second "she" is sung with unaccented beat, because only she herself knows that these magnificent appearances are exchanged for her body and soul. Will Macello lover here after knowing these? Here, Musetta is in a dilemma of love. Her song shows everything: various kinds of emotions and feelings entangled with each other, which bring the opera to the climax.

\section{3 The long for love music image of Musetta}

This period is the same with the first period. The speed returns to the A tempo and the music is still dotted half notes. Under the requirement of dolce emotion, continuous chords jump to the high pitch area gradually. In addition, Musetta's chipper and free and easy personality is shown by several short-shifting notes naturally. The low pitch keeps going with three times continuously and then, which is changed a little. At the 45th bar, the emotion of the music begins to be encouraging. The speed of this period music is allegro moderato. And the strength becomes stronger and stronger. The melody and the accompaniment form a perfect interval of octave chord together. The intervals sequence from low to high pitch. The objective of the composer in dealing with the emotion of the music is to express the concern of the chief actress in the reply of the counterpart after she expresses her love. She wants to be confirmed by her past lover. In the end of the period, the composer through the music into the climax with an octave chord arpeggio. Then, the period is ended with a quaver clearly. The application of quaver and quaver rest in the accompaniment make the music become more active, which completely show the rakish musical image of Musetta, as if she is waiting for her own beautiful love and the reply of her lover seriously.

The long for love musical image of Musetta can be divided into two parts. The first part (37-44 bars) is about her memories about the past sweet love. The second part (45-52 bars) is about her desire for love. In the first part, the speed of the music returns to the original one, which is light and the melody is fair-sounding. The music clams down gradually, because Musetta is recalling the sweet days with Macello. This period of music is very gentle, which express the inner world of Musetta. She thinks fondly of the past pleasant days. However, she doesn't confident enough to expect love. She wants to forget the happy times. However, she can not make it. Moreover, her past lover is exactly in front of her. Looking at him, she remembers the past times. She is filled with depression and doesn't know what to do. In the next 45 to 52 bars, the emotion is raised, because she know that she will either erupt in love or die in love. She longs for love and hope to get together with her lover again. This period brings the story to the climax again. "You don't want to confide intimate things to me and I will let you bother yourself with sadness all the day" is a sentence Musetta sings to Macello, because she has already expressed her inner world. She hopes to know 
what is Macello thinking about. Macello looks at her. Musetta knows Macello still loves her. Therefore, Puccini adopted a clear end for the music, which summarized Musetta's thoughts and her unrestrained individual character clearly.

\section{Conclusion}

Puccini revealed the inner world and emotion changes of Musetta with his unique "verism" can Puccini-style arias. Starting from the character personality, drama development, emotion changes and theme revelation, the arias become the core link to perfectly shape the musical image of the opera character. The phenomenon of disoperation between the arias and plots chased by the show-off of the techniques of traditional opera is changed completely. Puccini develops the music completely according to the development of the inner world of the character. The connections between melodies and chords are the real emotions of the characters. His "verism" advocates the principle of "people first", where the inner emotions of characters are taken as the starting points to shape the whole music images of the characters. His drama themes and music themes play important accumulative roles in music images of characters.

\section{References}

1. Shi Yuan, Puccini --- An Immortal Italian Opera Composer, Beijing, People's Music Publishing House, 1999.

2. Chen Lixin, Puccini in Records, Shanghai, World Publishing Corporation, 2001.

3. He Xidie, Appreciation for 365 Foreign Ancient and Modern Famous Musical Compositions, People's Music Publishing House, 2003.

4. Zhou Feng and Zhu Xiaoqing, Collection of Foreign Musical Compositions, Shanghai Music Publishing House, 2004.

5. Li Weibo, Development History of Western Vocal Music, World Publishing Corporation, 1999.

6. Shang Jiaxiang, Development History of European Music, Huale Press, 2003.

7. Yu Runyang, Western Music History, Shanghai, Shanghai Music Publishing House, 2001.

8. Translated by Ding Yi, Western Opera and Drama Set, International Culture Publishing House, 1999.

9. Wang Peilun, Opera Dictionary, International Culture Publishing House, 1999.

10. Zhang Wei and Xie Lili, Puccini, Oriental Press, 1996. 